\title{
0 império do samba, trinta e seis anos depois
}

\author{
Carlos Eduardo Dias Souza'
}

\section{Resenha do livro:}

VALENÇA, Rachel. Serra, Serrinha, Serrano: o império do samba. Rio de Janeiro: Record, 2017. 433 páginas.

Convidada para falar numa mesa sobre carnaval, organizada no Museu Nacional do Rio de Janeiro, em 04 de setembro de 2017, uma das autoras de Serra, Serrinha, Serrano: o império do samba foi apresentada ao público como historiadora. Logo ao iniciar sua fala, a autora, Rachel, fez uma correção: ainda que interessada nas coisas do universo de Clio, ela não era historiadora de formação. Em seguida, no entanto, ponderou: "posso ser historiadora, desde que do Império Serrano".

A reedição da obra pela editora Record, em 2017, faz jus à ponderação: a sua primeira edição, há muito esgotada e escrita com seu então esposo Suetônio Valença, é de 1981 e cobre histórias da escola recolhidas por ambos desde antes mesmo da fundação do Império Serrano, em março de 1947. Explique-se: a escola remonta a uma anterior, o "Prazer da Serrinha", dirigida por Alfredo Costa, que considerava a agremiação "uma extensão de sua família" (Valença, 2017: 53). Insatisfeitos com a condução arbitrária de Costa na agremiação, um grupo de sambistas da comunidade matriz da escola, o morro da Serrinha, decidiu deixar de desfilar nas vésperas do carnaval de 1947, saindo num bloco montado de última hora para aquele carnaval. Apoiados por um sambista de destaque na cena carioca, Elói Antero Dias - o Mano Elói -, e recebendo o apoio de outros

1 Turismo e Hotelaria SENAC-RJ - Rio de Janeiro, RJ - Brasil - kdudiaz@gmail.com 
sambistas egressos de uma escola da Tijuca e da Portela, formou-se, em 23 de março de 1947, uma comissão, reunida na casa de tia Eulália, que decidiu pela fundação de uma nova escola. Na reunião, foram decididos seu nome e suas cores: Império Serrano, nome sugerido por Sebastião de Oliveira, o Molequinho, com as cores verde e branco, propostas por Antenor (Valença, 2017: 74-75). Daí surgira outra marca do Império Serrano: a democracia. Sob as bênçãos de São Jorge, começava a história do Império Serrano, agora eternizada "no livro" (como ele é conhecido pelos imperianos) e ampliada por Rachel Valença nesta nova edição, que cobre os carnavais da escola de 1982 até a preparação para 0 desfile de 2017.

Na introdução à primeira edição, os autores confessam ser o livro "um misto de paixão e história" (Valença; Valença, 1981, p. XIII). Baseados em relatos de uma plêiade de bambas e outros membros da escola, com os quais conviviam desde o início da década de 1970, os autores, especialmente Rachel na reedição de 2017, deixam evidente que é a paixão que guia a escrita. Ao fazê-lo, não é o relato historiográfico que perde, pelo contrário: ao puxar pelos fios da memória, seja a das pessoas entrevistadas, seja a deles próprios, relatos, dramas e sambas antológicos da escola, Rachel e Suetônio apresentam ao leitor uma escola de samba em toda sua tradição e esplendor, mas também em seus dilemas, conflitos e derrotas. Tal tipo de abordagem, que valoriza a experiência cotidiana e a ação daqueles que por séculos estiveram invisibilizados da narrativa historiográfica, já é corrente na historiografia há algumas décadas. A categoria "experiência”, evidenciada pelo inglês Edward Thompson (2001), propõe um olhar mais adiante à falsa dicotomia entre estrutura e agência, questão também cara às ciências sociais. Para além de uma possível determinação de tom classista, decorrente de fatores como a pobreza da periferia na qual se fundou o Império ou da atuação política de estivadores sindicalizados e que participaram da fundação da escola, Rachel e Suetônio se permitem entender a formação da escola a partir de múltiplas experiências - o que inclui a ambos, não nascidos na Serrinha e moradores de área nobre do Rio de Janeiro com formação universitária. Ainda que não sendo da Serrinha e nem tendo visto o Império nascer, ambos viram o Império lutar e também o viram vencer.

É nesse sentido que a escola é apresentada como resultado de tensões e formações específicas que fogem à perspectiva que já esteve mais em voga, que toma a escola de samba como uma evidência da consciência de classe e da criatividade inata das camadas populares, resultado de sua "improvisação". Pois a escola não nascera de um conflito dentro da própria comunidade? Aqui, porém, é que ganha força a narrativa da escola sobre si mesma, constantemente 
corroborada pelos autores: formada a partir da migração de pessoas desalojadas de suas casas no centro do Rio no processo de reordenamento urbano que culminaria nas reformas do começo do Século XX, a Serrinha e outros subúrbios da região de Madureira recebiam não apenas migrantes que já moravam na cidade do Rio, mas também outros que chegavam naquele momento, como baianos e até mesmo portugueses. Do sul de Minas Gerais e do vale do rio Paraíba fluminense e paulista também vieram pessoas, muitas em busca de trabalho na então capital em contexto da ainda recente abolição da escravidão. $O$ trem facilitava os descolamentos de todos esses grupos, cada um trazendo consigo e à sua maneira tradições festivas, que iam dos ranchos e blocos familiares ao jongo e ao caxambu: o jongo com o canto e a dança e o caxambu, a batida dos tambores, segundo Antônio Rufino dos Reis, jongueiro e um dos fundadores da coirmã Portela. "É a mesma coisa", diria Dona Eulália, a imperiana número 1 (Valença, 2017: 39).

"Pra sambar o ano inteiro", o Império ainda contaria com proteção de São Jorge, a quem a escola fora oferecida como afilhada após recusa da Portela, mordida após os "quatro anos de vitória sem igual" do Império nos carnavais de 1948 - sua estreia retumbante no préstito carnavalesco! - até o de 1951. A religiosidade de matriz africana evidenciava-se nos terreiros de Dona Marta, de Vovó Maria Joana Rezadeira (com seu famoso banquete para os cachorros) ou nos de Doroteia e Vieira, esses últimos no bairro vizinho de Oswaldo Cruz, nos quais também se dançava jongo (Valença, 2017: 39-50). Mano Elói, aliás, chegou a gravar discos para a Odeon com pontos de umbanda e registrados como "macumba" ainda na década de 1930. Para os autores, era sinal de seu prestígio, confirmado pela presidência da Federação Brasileira das Escolas de Samba, fundada em 1947, a partir da antiga associação, da qual também fora presidente (Valença, 2017: 84). É assim que o livro é iniciado, apresentando as "vigas-mestras"2 da escola e reforçando as matrizes afro-brasileiras do samba do Império Serrano nos dois primeiros capítulos.

Duas dessas vigas são apresentadas no terceiro e no quarto capítulos do livro: Mano Décio da Viola e Silas de Oliveira, respectivamente. A parceria de ambos legou sambas antológicos, como "Heróis da Liberdade", ${ }^{3}$ samba do carnaval de 1969. Toda a riqueza poética de Silas fica evidente em sambas como "Aquarela brasileira", composto para o carnaval de 1964. Esses e outros sambas

2 O termo "viga-mestre" aparece no samba-enredo do carnaval de 1992 e faz referência a Silas de Oliveira, maior compositor de sambas-enredo da escola e que deu novo formato à sua composição nos anos 1950. Neste texto, o termo está sendo utilizado também em referência aos mais velhos e fundadores da escola. 
dos quais Silas participou como autor, dentre eles "Cinco bailes tradicionais da história do Rio", escrito por ele junto a Bacalhau e Ivone dos Santos Lara - a Dona Ivone Lara, nome artístico da pioneira e mais profícua autora de sambas-enredo - para o carnaval de 1965, aproximam o samba do gênero épico, segundo Rachel e Suetônio. Construído a partir de mecanismos próprios à epopeia, iniciada com a invocação, seguida da proposição e daí passando à narrativa propriamente dita (Valença, 2017: 156), os sambas que Silas legou para o Império e para o mundo fazem parte do rol de inovações inaugurado pelo "menino de 47", como também é conhecido o Império Serrano. Os "sambas-lençol", como ficaram conhecidas as composições de Silas, que "cobriam" praticamente todos os temas abordados no enredo, deram o formato hoje padrão dos sambas de enredo no país, ainda que sem a riqueza de detalhes, como o vocabulário sofisticado e as melodias solenes, nos moldes de seu percursor (Mussa; Simas, 2010: 55-70).

Os Capítulos 3 ao 13 giram em torno da história de ambos. Silas faleceu antes dos autores chegarem à escola no ano de 1972. Já Décio chegou a ser entrevistado por Rachel em 1978 para a primeira edição do livro. Seguindo a lógica que preside a escrita do livro, é a memória dos autores que guia a narrativa. Não seria por acaso: na introdução a esta segunda edição, Rachel deixa claro que este é um "livro-exaltação" (Valença, 2017: 27). Sua participação na escola, de interessada no carnaval à componente nos desfiles, incluindo passagens rápidas pela bateria e outras mais demoradas em cargos administrativos, incluindo a direção do Império, fez da autora "a feliz depositária da memória" dessa que é hoje também sua escola, como é de outras tantas famílias, que lhe confiaram relatos, imagens e heranças (Valença, 2017: 22-24). Conforme já havia apontado Maurice Halbwachs (1990) em seus escritos sobre memória, depoimentos como este de Rachel possuem sentido dentro de um quadro de referência comum às pessoas que vivem do samba no Rio de Janeiro. O cotidiano, a história miúda, as experiências de membros dessas famílias ganham vida exatamente por Rachel ser quem é: imperiana, e pelo livro ser o que se propõe ser: um livro-exaltação. Em cena, pois, está uma espécie de comunidade afetiva baseada num fundamento comum e que tem pontos de aproximação suficientes para que os depoimentos recolhidos não sejam apenas memórias de um passado que já não existe, mas evidências do que significa ser imperiano ontem e hoje.

Assim, é pela trajetória de Décio e Silas que os autores reforçam o significado da existência cotidiana nos subúrbios de Madureira a Vaz Lobo, onde se localiza a Serrinha, a meio caminho entre os dois. Ali era reduto de jongo e de caxambu - e o Jongo da Serrinha, único remanescente na região metropolitana do Rio hoje, confirma a força dessa tradição. Era também reduto de sambas 
- bastaria subir a Balaiada, rua na qual foi fundado o Império, para ouvir uma melodia vagando pela noite. A vida social ao redor dessas duas expressões culturais não se limitava à escola de samba ou ao carnaval, portanto: compor, cantar e ouvir sambas, bem como participar de rodas de jongo na região era parte do cotidiano de seus moradores. A própria escola Prazer da Serrinha possuía intensa vida social e cultural, mesmo com todo o autoritarismo de Seu Alfredo. Foi nela que Silas se aproximara de Décio; era dela que o pessoal saía para Festa da Penha em outubro, onde havia barracas de imperianos como Zacarias, que servia de ponto de encontro do pessoal da Serrinha desde os tempos da escola do Seu Alfredo. Na casa dos pais de Zacarias, frequentada por chorões do garbo de Pixinguinha, Donga, João da Baiana e Heitor dos Prazeres, vivia-se o samba para além daquilo que a escola representava, ainda que a tivessem como núcleo congregador de sociabilidade, posto que foi ela que reuniu as tradições do pessoal do choro - e Pixinguinha não era lá fã número 1 do samba -, do samba urbano do centro da cidade com o caxambu do pessoal que vinha de Minas ou de São Paulo de trem (Valença, 2017: 118).

Na Serrinha, portanto, pessoas de formação, em princípio, distante do samba, como Silas, cujo pai era protestante, reuniram-se em prol de um ideal comum: experimentar a liberdade. $\mathrm{O}$ ideal de democracia, que orienta até hoje as gestões do Império Serrano, deve ser lido, portanto, para além do mito fundador. Claro que havia figuras de proa na nova escola, como Tia Eulália, figura presente no cotidiano da escola desde a escolha do samba à observação da bateria, ou Mano Elói, que era ogã em macumbas na cidade, mas também líder portuário, atuando na Sociedade de Resistência dos Trabalhadores em Trapiche e Café, associação sindical de maioria negra. Porém, mesmo pessoas, em princípio, distantes da comunidade, como o militante da imprensa Irênio Delgado, imperiano à primeira vista, logo seriam incorporados à escola. Os "quatro anos de vitórias sem igual” do Império de 1948 a 1951 aumentariam a sua fama, trazendo mais gente, como a cantora de rádio Marlene, para a escola. Ainda assim, toda essa fama não era suficiente para garantir boa existência aos seus. O próprio Silas passou por graves problemas financeiros e familiares, a despeito de sua genialidade (Valença, 2017: 148-153).

Ao problema de financiamento da escola e de seus membros somou-se, na década de 1970, a "exigência" de novos quesitos "não oficiais" para o julgamento dos desfiles: o visual ganhava primazia, o que demandava maiores recursos. A figura do carnavalesco ganharia importância nesse momento, como aquele que propõe o enredo e sua composição, influindo, por vezes, até mesmo na escolha do samba enredo. Ainda que o estreante Fernando Pinto tenha conseguido 
mesclar a tradicional proposta do Império com a inovação exigida pelos novos tempos, no contexto mais amplo do desfile carnavalesco na cidade do Rio era o luxo que se destacaria como o elemento fundamental na composição dos desfiles, em grande medida como resultado dos aportes financeiros de patronos ligados ao jogo do bicho, especialmente em escolas até então de pouco destaque, como a Mocidade Independente de Padre Miguel e a Beija Flor. Segundo Myrian Sepúlveda dos Santos, a espetacularização do desfile teria, por isso, promovido uma profissionalização geral, ainda que por vezes atendesse também aos quesitos considerados tradicionais, como o mestre-sala e a porta-bandeira, que mantêm sua importância na avaliação geral da escola. Desde então, ainda segundo Santos, a ampliação da base social das escolas, fruto do sucesso e da contratação de profissionais, pareceu distanciá-las de seus elementos-chave (ou suas vigas-mestras), como os grupos negros moradores de favelas, os adeptos de religiões de matriz africana e ainda as camadas populares em geral que acompanhavam as escolas sem necessariamente nelas desfilar (Santos, 2006: 134-137). A força e representatividade das escolas e a política dentro delas passaria a depender, cada vez mais, de tais dinâmicas em desenvolvimento no "mundo externo" às agremiações, colocando em xeque elementos caros às suas histórias, como a presença e representatividade negra. ${ }^{4}$

Essa questão também fora discutida, ainda que de maneira distinta, por Luiz Costa Pinto em sua análise sobre o negro no Rio de Janeiro. No primeiro capítulo da segunda parte do livro "O negro no Rio de Janeiro: relações de raças numa sociedade em mudança”, originalmente publicado em 1953, o autor se propõe a discutir o que ele chama de "associações tradicionais", dentre elas as escolas de samba. $\mathrm{O}$ alvo era as associações "negras" em contexto de grande mudança social - o início do Século XX -, marcado por processos como a urbanização e a proletarização do negro (Costa Pinto, 1998: 218). Divididas pelo autor em associações tradicionais e as de novo tipo, interessava-lhe observar a dinâmica das relações raciais a partir da observação dos padrões associativos de grupos negros no espaço urbano, bem como sua influência nesses mesmos padrões. As escolas de samba aparecem como associações do tipo tradicional e de feição lúdica. Esse parece ser o mote que justifica sua conclusão de que "tudo isso na verdade resulta do esforço de poucos", o que esvaziaria, a seu ver, o

4 A mesma autora, no artigo "O batuque negro das Escolas de Samba”, destaca a ambiguidade do momento, pois, nos anos 70, as chegadas de grupos de classe média junto às escolas, como carnavalescos, também ajudaram a reforçar a apresentação de elementos afrobrasileiros nos desfiles. Daí o reconhecimento da força dessa cultura na exibição carnavalesca facilitaria, também, o recurso a ela como elemento de reconhecimento e autoestima entre aqueles que participam da produção do carnaval carioca (Cf. Santos, 1999). 
potencial associativo das agremiações para além daqueles com posições na escola e, mesmo entre eles, fora do contexto de preparação para o carnaval (Costa Pinto, 1998: 229). O conceito de público, entendido enquanto aquele que observa os desfiles e até aparece em um e outro evento de preparação para os mesmos, reforçaria seu argumento de que as escolas não teriam vida própria depois do carnaval. A despeito da evidente presença de elementos que remeteriam à influência africana na música e na coreografia, o "sincretismo avassalador" causado pelas mudanças em contexto urbano não necessariamente fariam da escola um espaço de "tomada de consciência negra": elas eram divertimento de pobre, nada mais. Como os negros eram a maioria dos pobres, justificava-se sua presença ali, ainda que apenas como público.

Não é bem isso que se depreende dos relatos de Rachel no livro. A questão é complexa, mas uma lembrança destacada pela autora é ilustrativa: afastada da ala das crianças no carnaval de 1994, a responsabilidade do ensaio desta ala ficara a cargo de "dois brancos!", nas palavras do compositor Carlinhos, algo espantado com a decisão da nova diretoria (Valença, 2017: 297). O interessante da fala é notar como as escolas de samba vão além de um mero espaço de divertimento, mas principalmente de construção de sociabilidades que não se limitam ao carnaval - Rachel era responsável pela ala há anos, junto de Alfredinho. A "família imperiana" transcende o carnaval e não se resume ao desfile: ela é o próprio Império, que faz dele o seu dia a dia (Valença, 2017: 378). Dessa família Rachel também faz parte. E é como imperiana de fé que Rachel assume a narrativa do livro da preparação do desfile de $1982 \mathrm{em}$ diante, destacando principalmente as dinâmicas políticas internas da escola como possível matriz explicativa para 0 momento vivido por ela. "Dono de muitas vitórias, da qual eu sou testemunha, e honro suas glórias", o Império relembrado pela autora ganha novas cores dos Capítulos 17 ao 29, última parte do livro. As disputas eleitorais, os candidatos, suas equipes e as fofocas surgidas nessa dinâmica um tanto conflituosa ganham vida em seu relato, em grande medida resultado de sua participação mais ativa na escola, que incluía a direção da ala Baleiro Bala, voltada para as crianças, desde 1980, e também passagens como secretária do Conselho Deliberativo a responsável pelo departamento cultural e ainda a vice-presidência da escola.

O padrão de apresentação dos carnavais segue o dos outros capítulos: a preparação para o desfile e o samba-enredo do ano são o centro da narrativa, a partir do qual são contadas as histórias. A diferença agora é que Rachel as conta de dentro, e o que antes talvez soasse como recurso à memória de tempos passados para compensar as perdas e problemas presentes, na verdade confirma o argumento central da obra: o Império como um "ato de amor". Mesmo os conflitos 
presenciados pela autora passam pela comunhão de pessoas que amavam tanto a escola e que, cada um à sua maneira, buscaram fazer dele o que sempre foi: um grande campeão, inovador sem abandonar sua tradição. Assim são apresentadas as ações do presidente Jamil (o "Cheiroso", figura extremamente agregadora) e suas aproximações com pessoas como o bicheiro Carlinhos Maracanã, presidente da Portela que articulou junto à antiga Associação das Escolas de Samba a manutenção do Império no grupo especial do carnaval após o desastrado desfile de 1981 (Valença, 2017: 236). Enquanto internamente à escola Jamil apoiava ações como o Botequim do Império, que reforçava os laços comunitários e também entre sambistas da cidade na quadra da escola (Valença, 2017: 237), externamente o presidente buscava apoio de quem pudesse oferecer, como o carnavalesco Fernando Pamplona, que tinha grande simpatia pelo Império. Pamplona sugeriu enredos e carnavalescos para a escola, dentre eles as novatas Rosa Magalhães e Lícia Lacerda, que para o desfile de 1982 propuseram como título do enredo o controverso "Bum Bum Paticumbum Prugurundum" (Valença, 2017: 238). Quem diria que dali sairia mais um samba memorável na já vasta galeria de sambas-enredo imperianos?

A década de 80, porém, colocava novos desafios. A fundação de uma nova associação, a LIESA, a liga que passaria a coordenar o carnaval do grupo especial carioca quando da fundação do Sambódromo da Marquês de Sapucaí, em 1984, pode ser destacado como um deles (Valença, 2017: 255-256). Desde então, além do controle da política interna da escola, era preciso criar boas relações junto à liga, cuja iniciativa partira de escolas controladas por contraventores. Foi nessa mesma década que política interna do Império pareceu desandar. Mesmo com desfiles ainda alegres, como os de Renato Lage, também indicado por Pamplona (inclusive responsável pelo primeiro enredo patrocinado da história do carnaval, mas não por iniciativa da empresa, e sim da escola, que em 1985 falaria sobre cerveja) (Valença, 2017: 256), a ascensão de escolas como a Beija-Flor e seus desfiles deslumbrantes (como "Ratos e Urubus, larguem a minha fantasia”, em 1989) pareciam demandar novas formas de gestão do carnaval. Amargando posições ruins no desfile, figuras "salvadoras" se apresentaram, como Oscar Lino da Costa, que prometera fazer uma limpa na escola (Valença, 2017: 277), o que não adiantou: após o desfile de 1991 a escola era rebaixada. É nesse momento que a política interna da escola ganha importância no texto, até como resultado dos anos de participação de Rachel naquela família imperiana.

Assim é apresentada Neide Coimbra, a "Cigana guerreira" que amava tanto a escola que a tratava como se fosse sua casa - o que às vezes causava problemas, como quando a presidente viajava e levava consigo as chaves da quadra (Valença, 
2017: 334). De coadjuvante de presidentes como o próprio Jamil, que voltava eleito em 1992, à fiadora de figuras controversas, como Marquinhos dos Anéis, Neide desponta na narrativa como inteligente articuladora, e não apenas para fins de políticos. Ainda que a Cigana viesse ela própria a assumir a presidência entre $1999 \mathrm{e}$ 2005 e mesmo que tivesse em seu histórico ações questionáveis a fim de favorecer os seus, a sua chegada à direção promoveu a autoestima e a confiança da família imperiana, da qual ela também fazia parte (Valença, 2017: 323), após os sucessivos rebaixamentos de 1991, 1997 e 1999. Boas relações com a LIESA e a valorização da tradição da escola, ao revitalizar a Velha Guarda Show, por exemplo, foram pontos altos de sua gestão, também marcada por controvérsias eleitorais (Valença, 2017: 333). Numa dessas controvérsias ganhara força Vera Lúcia, viúva de ex-presidente e que encabeçava a oposição à Neide. Vera assumiria ainda um mandato tampão em 2011 (após a gestão de Humberto Carneiro, da qual Rachel fez parte como vice-presidente) e retornaria eleita, não sem controvérsias, em 2015.

A experiência de Rachel, somada às suas memórias, faz de Serra, Serrinha, Serrano "um ato de amor", tal qual fora cantado no desfile de 1992. A escola é relatada quase como uma família, cujos sentidos extrapolam desfiles, territórios e mesmo disputas políticas. "A minha história já fala por mim", diz o samba-enredo defendido no desfile de 2017, cujos preparativos Rachel chega a esboçar, e que fora vencido pela escola, o que the valeu o retorno ao grupo especial neste ano de 2018. Este livro, como parte da história da escola, é também um recurso precioso para que se possa saber mais não apenas sobre ela, mas também sobre temas, como formas de organização e sociabilidade populares, religiosidades em espaços periféricos e, principalmente, as contribuições de dinâmicas culturais afro-brasileiras na formação do subúrbio carioca. "Abra meu livro, pois tu sabes ler", diz o samba de Beto Sem Braço, Jangada e Maurição para o carnaval de 1992. Pois era à edição de 1981 que eles se referiam. Que bom que Rachel faz deste livro, agora em nova versão, um registro dessa que é uma das manifestações mais exuberantes de nosso país, as escolas de samba, contada por meio das histórias daquele menino de 1947, o hoje septuagenário Império Serrano.

\section{Referências}

COSTA PINTO, Luiz Aguiar. O Negro no Rio de Janeiro. Relações de Raças numa Sociedade em Mudança. $2^{\mathrm{a}}$ ed. Rio de Janeiro, Editora UFRJ, 1998, 355 p.

HALBWACHS, Maurice. A memória coletiva. São Paulo, Vértice, 1990, 197 p.

MUSSA, Alberto; SIMAS, Luiz Antônio. Samba de enredo: história e arte. Rio de Janeiro, Civilização Brasileira, 2010, 238 p. 
SANTOS, Myrian Sepúlveda. Mangueira e Império: a carnavalização do poder pelas escolas de samba. In: ZALUAR, Alba; ALVITO, Marcos (Orgs.). Um século de favela. $5^{\text {a }}$ ed. Rio de Janeiro, FGV, 2006.

SANTOS, Myrian Sepúlveda. O batuque negro das Escolas de Samba. In: Estudos AfroAsiáticos. Brasília, n. 35, 1999, pp. 43-66.

THOMPSON, Edward Palmer. A peculiaridade dos ingleses e outros artigos. Organizado por NEGRO, Antonio Luigi; SILVA, Sergio. Campinas, Editora Unicamp, 2001, 288 p.

VALENÇA, Rachel; VALENÇA, Suetônio. Serra, Serrinha, Serrano: o império do samba. Rio de Janeiro, Editora Record, 1981, 482 p.

VALENÇA, Rachel. Serra, Serrinha, Serrano: o império do samba. Rio de Janeiro: Record, 2017, 433 p.

Recebido em 31/01/2018

Aprovado em 07/11/2018

\section{Como citar esta resenha:}

SOUZA, Carlos Eduardo Dias. O império do samba, trinta e seis anos depois. Contemporânea - Revista de Sociologia da UFSCar, v. 8, n. 2, jul.-dez. 2018, pp. 678-696. 